\title{
Uncomplicated Laparoscopic Cholecystectomy to Drain or not to Drain
}

\section{Selim Said Abdel-Rahman EL-Nemr, Ahmed Mohamed El-Sayed, Abdel-Galeel Kamal Abdel-Galeel Elwany *}

General Surgery Department, Faculty of Medicine, Al-Azhar University

* Corresponding Author: Abdel-Galeel Kamal Abdel-Galeel Elwany, E-mail: Surgelwany41@gmail.com

\begin{abstract}
Background: gallstones are present in about $10 \%$ to $15 \%$ of adult population. Between $1 \%$ and $4 \%$ of these adults become symptomatic every year. Laparoscopic cholecystectomy first performed by philippe Mouret in Lyon, France in the late 80s, has gained acceptance at the standard of care for patients requiring cholecystectomy. Laparoscopic cholecystectomy provides a safe and effective treatment for most patients with symptomatic gall stones. Laparoscopic cholecystectomy for acute cholecystitis is mainly performed after the acute cholecystitis episode subside because of the fear of higher morbidity and need for conversion from laparoscopic to open cholecystectomy.
\end{abstract}

Aim of the Work: the need for routine abdominal drainage in uncomplicated laparoscopic cholecystectomy. Benefits and harms of intra abdominal drains in uncomplicated laparoscopic cholecystectomy.

Patients and Methods: the study included 50 patients from Al Azhar University Hospital and with chronic calcular cholecystitis in period from February 2016 to June 2018. They were randomly assigned into one of the two study groups: Group I: with tubal drains; Group II: without drains. The later group wasn't selected except after making sure that a drain is not required by the operating surgeon. Patients were selected on the basis of the following criteria.?? Ethical approval from local ethical committee of surgery department was obtained.

Results: data obtained from the present study were selected statistically analysis computed using SPSS. Continuous data were expressed in the form of mean + SD while categorical data were expressed in the form of count and percent. Comparison of continuous data was performed utilizing student $\mathrm{t}$ test, while categorical data were done using chi-square test. $\mathrm{P}$ value less than 0.05 was considered statistically significant. In group A (with drain) according to the sex is arranged as 7 male patients and 18 female patients, according to the age is arranged between 23-60 years and according to BMI is arranged between $18-30\left(\mathrm{~kg} / \mathrm{m}^{2}\right)$ in group B (no drain) according to the sex is arranged as 5 male patients and 20 female, according to the age is arranged between 25-60 years and according to the BMI is arranged between $20-35\left(\mathrm{~kg} / \mathrm{m}^{2}\right)$. No statistically significant differences between the two studied groups according to domographic data.

Conclusion: use of drain didn't result in reduction of postoperative complications. It was also associated with prolonged operative time, higher pain levels and longer hospital stay.

Keywords: Uncomplicated Laparoscopic Cholecystectomy, Pneumoperitoneum.

\section{INTRODUCTION}

Gallstones are present in about $10 \%$ to $15 \%$ of adult population. Between $1 \%$ and $4 \%$ of these adults become symptomatic every year ${ }^{(1)}$.

Laparoscopic cholecystectomy first performed by philippe Mouret in Lyon, France in the late 80s, has gained acceptance at the standard of care for patients requiring cholecystectomy.

Laparoscopic cholecystectomy provides a safe and effective treatment for most patients with symptomatic gall stones ${ }^{(2)}$.
Laparoscopic cholecystectomy for acute cholecystitis is mainly performed after the acute cholecystitis episode subside because of the fear of higher morbidity and need for conversion from laparoscopic to open cholecystectomy. Despite the many advantages of laparoscope over open surgery, many patients complain about referred pain to the shoulder during the postoperative course (3). High pressure pneumoperitoneum using carbon dioxide gas was accused for those complications ${ }^{(4)}$.

A drainage tube is inserted to reduce pain after laparoscopy ${ }^{(5)}$. Routine drain use 
after Laparoscopic cholecystectomy is still debatable. The main indication for drain use after Laparoscopic cholecystectomy is to prevent a biloma or hematoma. According to the Cochrane Database systemic Review; randomized clinical studies show no benefit of a drain ${ }^{(1)}$.

Drains are used after Laparoscopic cholecystectomy to prevent abdominal collections. However, drain use may increase infective complications and delay patient discharge ${ }^{(\mathbf{1})}$.

The insertion of a sub-hepatic drain after elective Laparoscopic cholecystectomy increases post-surgical pain, prolongs hospital stay and do not prevent the occurrence of intra-abdominal abscesses ${ }^{(6)}$.

There is no proof that the drain was useful in elective uncomplicated Laparoscopic cholecystectomy ${ }^{(7)}$.

Recently, Kim et al. concluded that routine use of a drain after Laparoscopic cholecystectomy for an acutely inflamed gallbladder had no effect on the postoperative morbidity ${ }^{(8)}$.

In fact, although the issue of drain use in open cholecystectomy has been adequately addressed by prospective randomized trials, there is lack of evidence on the usefulness of drains in elective Laparoscopic cholecystectomy, the surgeons follow their beliefs and bias on this debate ${ }^{(9)}$.

\section{AIM OF THE WORK}

The aim of the study is to assess: The need for routine abdominal drainage in uncomplicated laparoscopic cholecystectomy. Benefits and harms of intra abdominal drains in uncomplicated laparoscopic cholecystectomy.

\section{PATIENTS AND METHODS}

The present study is a randomized controlled study.

\section{PATIENTS}

The study included 50 patients from $\mathrm{Al}$ azhar University Hospital and with chronic calcular cholecystitis in period from February 2016 to June 2018. They were randomly assigned into one of the two study groups: Group I: with tubal drains; Group II: without drains. The later group wasn't selected except after making sure that a drain is not required by the operating surgeon. Patients were selected on the basis of the following criteria. Ethical approval from local ethical committee of surgery department was obtained.

\section{Inclusion criteria}

Patients were selected to participate in the study if they have chronic calcular cholecystitis.

\section{Exclusion criteria}

1. Acute cholecystitis.

2. Acute Cholangitis.

3. Acute Pancreatitis.

4. Previous major abdominal operation.

5. Intra-operative bleeding \& biliary leakage.

6. Patient requires common bile duct exploration or any other additional procedure.

7. Bleeding tendency.

8. Patient refusal to laparoscopic cholecystectomy.

9. Difficult cases require additional procedures e. $\mathrm{g}$ adhesion, pyocele.

\section{METHODS}

\section{All participants were subjected to the following:}

- History taking: personal history, history of present illness, past history and family history.

- Clinical examination; general and local abdominal examination.

- Routine laboratory investigations; CBC, liver function test, kidney function test and coagulation profile.

- Abdominal ultrasonography.

- Laparoscopic cholecystectomy.

\section{Operative technique:}

All patients were subjected to automatic insufflations by carbon dioxide under $14 \mathrm{mmHg}$ pressure. The patients were divided into two groups; group I with tubal drain (25 patients), group II without drain (25 patients).

\section{Postoperative care:}

The perioperative variables (operative time, postoperative pain, and postoperative hospital stay) were evaluated. We checked for postoperative pain using a visual analog scale (VAS) from 0 (no pain) to 10 (worst pain imaginable) $12 \mathrm{~h}$ after the operation. 


\section{Statistical Analysis}

Data obtained from the present study were selected statistically analysis computed using SPSS. Continuous data were expressed in the form of mean $+\mathrm{SD}$ while categorical data were expressed in the form of count and RESULTS percent. Comparison of continuous data was performed utilizing student $\mathrm{t}$ test, while categorical data were done using chi-square test. $\mathrm{P}$ value less than 0.05 was considered statistically significant.

Table (1): Comparison between the two studied groups according to demographic data

\begin{tabular}{|c|c|c|c|c|c|c|}
\hline & \multicolumn{2}{|c|}{$\begin{array}{c}\text { Group A } \\
(n=25)\end{array}$} & \multicolumn{2}{|c|}{$\begin{array}{c}\text { Group B } \\
(n=25)\end{array}$} & \multirow{2}{*}{ Test of sig. } & \multirow{2}{*}{$\mathbf{p}$} \\
\hline & No. & $\%$ & No. & $\%$ & & \\
\hline \multicolumn{7}{|l|}{ Sex } \\
\hline Male & 7 & 28.0 & 5 & 20.0 & \multirow{2}{*}{$\begin{array}{c}X^{2}= \\
0.439\end{array}$} & \multirow{2}{*}{0.508} \\
\hline Female & 18 & 72.0 & 20 & 80.0 & & \\
\hline \multicolumn{7}{|l|}{ Age (years) } \\
\hline Min. - Max. & \multicolumn{2}{|c|}{$23.0-60.0$} & \multicolumn{2}{|c|}{$25.0-60.0$} & \multirow{3}{*}{$\mathrm{t}=0.140$} & \multirow{3}{*}{0.889} \\
\hline Mean \pm SD. & \multicolumn{2}{|c|}{$41.96 \pm 10.43$} & \multicolumn{2}{|c|}{$42.36 \pm 9.79$} & & \\
\hline Median & \multicolumn{2}{|c|}{42.0} & \multicolumn{2}{|c|}{42.0} & & \\
\hline \multicolumn{7}{|l|}{ BMI $\left(\mathrm{kg} / \mathrm{m}^{2}\right)$} \\
\hline Min. - Max. & \multicolumn{2}{|c|}{$19.0-38.0$} & \multicolumn{2}{|c|}{$20.0-38.0$} & \multirow{3}{*}{$\mathrm{t}=0.569$} & \multirow{3}{*}{0.572} \\
\hline Mean \pm SD. & \multicolumn{2}{|c|}{$27.76 \pm 4.60$} & \multicolumn{2}{|c|}{$28.48 \pm 4.34$} & & \\
\hline Median & \multicolumn{2}{|c|}{28.0} & \multicolumn{2}{|c|}{28.0} & & \\
\hline
\end{tabular}

$\chi^{2}, \mathrm{p}: \chi^{2}$ and $\mathrm{p}$ values for Chi square test for comparing between the two groups

$\mathrm{t}, \mathrm{p}$ : $\mathrm{t}$ and $\mathrm{p}$ values for Student $\mathrm{t}$-test for comparing between the two groups

This table shows no statistically significant differences between the studied groups regarding the demographic data.

Table (2): Comparison between the two studied groups according to operative time

\begin{tabular}{|l|c|c|c|c|}
\hline \multicolumn{1}{|c|}{ Operative time } & $\begin{array}{c}\text { Group A } \\
(\mathbf{n = 2 5})\end{array}$ & $\begin{array}{c}\text { Group B } \\
(\mathbf{n = 2 5})\end{array}$ & t & P \\
\hline Min. - Max. & $55.0-85.0$ & $50.0-67.0$ & \multirow{2}{*}{$4.795^{*}$} & \multirow{2}{*}{$<0.001^{*}$} \\
\hline Mean \pm SD. & $65.28 \pm 8.98$ & $55.32 \pm 5.21$ & & \\
\hline Median & 64.0 & 54.0 & & \\
\hline
\end{tabular}

$\mathrm{t}, \mathrm{p}: \mathrm{t}$ and $\mathrm{p}$ values for Student $\mathrm{t}$-test for comparing between the two groups

*: Statistically significant at $\mathrm{p} \leq 0.05$

Patients in the drain group had significantly longer operative time when compared with patients with no drain.

Table (3): Comparison between the two studied groups according to postoperative complications

\begin{tabular}{|c|c|c|c|c|c|c|}
\hline \multirow{2}{*}{ Postoperative complications } & \multicolumn{2}{|c|}{$\begin{array}{c}\text { Group A } \\
(\mathbf{n}=25)\end{array}$} & \multicolumn{2}{|c|}{$\begin{array}{c}\text { Group B } \\
(n=25)\end{array}$} & \multirow{2}{*}{$\mathbf{X}^{2}$} & \multirow{2}{*}{$\mathbf{P}$} \\
\hline & No. & $\%$ & No. & $\%$ & & \\
\hline No & 13 & 52.0 & 12 & 48.0 & \multirow{2}{*}{0.080} & \multirow{2}{*}{0.777} \\
\hline Yes & 12 & 48.0 & 13 & 52.0 & & \\
\hline Wound infection & 4 & 33.3 & 1 & 7.7 & & \\
\hline Nausea and vomiting & 3 & 25.0 & 5 & 38.5 & \multirow{6}{*}{5.281} & \multirow{6}{*}{$\begin{array}{l}{ }_{\mathrm{pC}}^{\mathrm{MC}}= \\
0.604\end{array}$} \\
\hline Bile leak & 1 & 8.3 & 1 & 7.7 & & \\
\hline Fever & 2 & 16.7 & 2 & 15.4 & & \\
\hline Peri hepatic collection & 1 & 8.3 & 3 & 23.1 & & \\
\hline Acute pancreatitis & 1 & 8.3 & 0 & 0.0 & & \\
\hline Prolonged shoulder pain & 0 & 0.0 & 1 & 7.7 & & \\
\hline
\end{tabular}

$\chi^{2}$ : Chi square test for comparing between the two groups

${ }_{\mathrm{M}} \mathrm{p}$ : $\mathrm{p}$ value for Monte Carlo for Chi square test for comparing between the two groups 
No statistically significant differences between the studied groups regarding the postoperative complications.

Table (4): Comparison between the two studied groups according to pain

\begin{tabular}{|c|c|c|c|c|c|c|}
\hline \multirow[t]{2}{*}{ Pain } & \multicolumn{2}{|c|}{$\begin{array}{c}\text { Group A } \\
(\mathbf{n}=25)\end{array}$} & \multicolumn{2}{|c|}{$\begin{array}{c}\text { Group B } \\
(\mathbf{n}=\mathbf{2 5})\end{array}$} & \multirow[t]{2}{*}{ Test of sig. } & \multirow{2}{*}{$\mathbf{p}$} \\
\hline & No. & $\%$ & No. & $\%$ & & \\
\hline \multicolumn{7}{|l|}{ Grade } \\
\hline Mild & 9 & 36.0 & 5 & 20.0 & \multirow{3}{*}{$\begin{array}{c}\mathrm{X}^{2}= \\
1.587 \\
\end{array}$} & \multirow{2}{*}{0.208} \\
\hline Moderate - Severe & 16 & 64.0 & 20 & 80.0 & & \\
\hline \multicolumn{6}{|l|}{ Score } & \\
\hline Min. - Max. & \multicolumn{2}{|c|}{$3.0-9.0$} & \multicolumn{2}{|c|}{$2.0-6.0$} & \multirow{3}{*}{$\begin{array}{c}\mathrm{U}= \\
70.50^{*}\end{array}$} & \multirow{3}{*}{$<0.001^{*}$} \\
\hline Mean \pm SD. & \multicolumn{2}{|c|}{$6.0 \pm 1.55$} & \multicolumn{2}{|c|}{$3.56 \pm 1.19$} & & \\
\hline Median & \multicolumn{2}{|c|}{6.0} & \multicolumn{2}{|c|}{3.0} & & \\
\hline
\end{tabular}

$\chi^{2}, \mathrm{p}: \chi^{2}$ and $\mathrm{p}$ values for Chi square test for comparing between the two groups

$\mathrm{U}, \mathrm{p}$ : $\mathrm{U}$ and $\mathrm{p}$ values for Mann Whitney test for comparing between the two groups

*: Statistically significant at $\mathrm{p} \leq 0.05$

Patients in the drain group had significantly higher pain scores and higher frequency of moderate sever pain states when compared with patients without drain.

\section{DISCUSSION}

Laparoscopic cholecystectomy provides a safe and effective treatment for patients with gallstones (2). As it reduces postoperative pain with almost invisible scar, short hospital stay and earlier return to work (10). On the other side, many patients complain of abdominal pain, shoulder tip pain, and nausea/vomiting postoperatively (11). High pressure pneumoperitoneum using carbon dioxide gas was accused for those complications ${ }^{(4)}$.

Thus, a drainage tube is inserted ${ }^{(5)}$. The value of surgical drainage in open cholecystectomy is an issue that is not resolved till now ${ }^{\mathbf{( 1 2})}$. The same in laparoscopic cholecystectomy, where the lack of evidence on usefulness of drain is present. Again surgeons keep being divided among those placing a drain selectively, and those who never place a drain, based on their personal experience, beliefs, or bias ${ }^{(13)}$.

The present study aimed to assess the benefits and harms of routine abdominal drainage in uncomplicated laparoscopic cholecystectomy.To get this target accomplished, the study recruited 50 patients indicated for laparoscopic cholecystectomy. They were equally and randomly assigned into one of two groups: group 1 that had operative drain inserted and group 2 that had no drain. Comparison between the studied groups regarding age and sex didn't reveal statistically significant differences as intentionally designed.
In addition, we found no statistically significant differences between the studied groups regarding reported associated comorbidities. This is in agreement with the study of Ishikawa et al. ${ }^{(14)}$.

Allocation to drain or not to drain was non-randomized and based on surgeon preference according to intraoperative findings. Patient characteristics, operative results, and postoperative outcomes were compared between the two groups with univariate analysis. The study reported no statistically significant differences between groups regarding the associated medical conditions.

In the current study, patients in the drain group had significantly longer operative time when compared with patients with no drain. No statistically significant differences between the studied groups regarding the blood loss.

This is in harmony with the study of El-Labban et al. ${ }^{(15)}$. In their research, a controlled randomized trial was designed to assess the value of drains in elective laparoscopic cholecystectomy. During a twoyear period, 80 patients were simply randomized to have a drain placed (group A), an $8-\mathrm{mm}$ pentose tube drain was retained below the liver bed, whereas 80 patients were randomized not to have a drain (group B) placed in the subhepatic space. They reported a significantly longer operative time in the 
drain group when compared with the other group.

However, in the study of Picchio et al. (7) whose study was designed to assess the role of drains in laparoscopic cholecystectomy performed for non acutely inflamed gallbladder found no statistically significant differences between patients with drain and patients without regarding the operative time.

This may be explained by the variable surgical characteristics of the studied patients. Regarding the reported complications, the present study found no statistically significant differences between the studied groups. This results performed a retrospective review of all patients who had cholecystectomy for acute cholecystitis aiming to answer the question whether to drain or not to drain after cholecystectomy for acute calcular cholecystitis. They noted no statistically significant differences between patients using or not using drain regarding the reported postoperative complications.

In the study of Kim et al. ${ }^{(16)}$, patients were randomly assigned to undergo drain insertion (94 patients, $48.7 \%$, group A) or not (99 patients, 51.3\%, group B). In 18 cases (9.3\%), postoperative morbidities such as bleeding, bile leakage, wound infection or an abscess occurred, and there was no significant difference between the two groups.

In our study, patients in the drain group had significantly higher pain scores and higher frequency of moderate- severe pain states when compared with patients without drain. This is in line with the study of Tzovaras et al. ${ }^{(9)}$.

In a study of Kim et al. ${ }^{(8)}$, a controlled randomized trial was designed to assess the value of drains in elective laparoscopic cholecystectomy. 284 patients were randomized to have a drain placed (group A), whereas 281 patients were randomized not to have a drain (group B) placed in the subhepatic space. Postoperative pain was significantly increased in patients who had a drain placed; median visual analog scale (VAS) score was 5 (range 1 to 8 ) versus 3 (range 1 to 8 ), in the non-drained group ( $\mathrm{P}<$. 0001). Our data are also in agreement with the former study
Finally, we noted that patients in the drain group had significantly longer hospital stay when compared with patients in the other group. No mortality was reported. This is in agreement with the study of Georgiou et al. (17).

They evaluated drainage of the gallbladder bed after elective LC. One hundred sixteen patients were randomly allocated in two groups, sustained an uneventful LC, and were included in the study after an informed consent was obtained. Sixty-three patients were included in drainage group (YD) and 53 patients in non drainage group (ND). They reported a significantly longer hospital stay.

\section{CONCLUSION}

Use of drain didn't result in reduction of postoperative complications. It was also associated with prolonged operative time, higher pain levels and longer hospital stay.

\section{REFERENCES}

1. Gurusamy KS, Koti R, Davidson BR (2013): Routine abdominal drainage versus no abdominal drainage for uncomplicated laparoscopic cholecystectomy. Cochrane Database System Rev., 9:CD006004.

2. Dubois F (1995): Laparoscopic cholecystectomy, the French technique. In: Phillips EH, Rosenthal RJ. Operative strategies in laparoscopic surgery. Berlin, HeidelBery and New York, pp: 30-8.

3. Donatsky AM, Bjerrum F, Gögenur I (2013): Surgical techniques to minimize shoulder pain after laparoscopic cholecystectomy. A systematic review. Surg Endosc., 27(7):2275-82.

4. Perrakis E, Vezakis A, Velimezis G, Savanis G, Deverakis S, Antoniades $\mathrm{J}$ et al. (2003): Randomized comparison between different insufflation pressures for laparoscopic cholecystectomy. Surg Laparosc Endoscopic Percutaneous Tech., 13:245-9.

5. Abbott J, Hawe J, Srivastava $P$, Hunter D, Garry R (2001): Intraperitoneal 
gas drain to reduce pain after laparoscopy: Randomized masked trial. Obstet Gynecol., 98:97-100.

6. Ruiz-Tovar J, Ortega I, Santos J, Sosa L, Armañanzas L, Diez Tabernilla M, Calero A, Arroyo A, Oliver I, García S, Calpena R (2012): Is there any indication for inserting a drain in elective laparoscopic cholecystectomy? Cir Esp., 90(5):31821.

7. Picchio M, De Angelis F, Zazza S, Di Filippo A, Mancini R, Pattaro G, Stipa F, Adisa A, Marino G, Spaziani E (2012): Drain after elective laparoscopic cholecystectomy. A randomized multicentre controlled trial. Surgical Endoscopic., 26(10):281722.

8. Kim EY, You YK, Kim DG, Lee SH, Han JH, Park SK, Na GH, Hong TH (2014): Is a Drain Necessary Routinely After Laparoscopic Cholecystectomy for an Acutely Inflamed Gallbladder? A Retrospective Analysis of 457 Cases. J Gastrointestinal Surg., 18(5):941-6.

9. Tzovaras G, Liakou P, Fafoulakis F, Baloyiannis I, Zacharoulis D, Hatzitheofilou C (2009): Is there a role for drain use in elective laparoscopic cholecystectomy? A controlled randomized trial. Am J Surg., 197(6):759-63.

10. Talamini MA, Gadacz TR (1991): Laparscopic equipment and instrument. In: Zucker KA, Baily RW, Reddick EJ, editors. Surgical Laparoscopy. Missouri: Quality Medical Publishing Inc., St. Louis, pp: 45-6.

11. Sarli L, Costi R, Sansebastiano G, Trivelli M, Roncoroni L (2000):
Prospective randomized trial of lowpressure pneumoperitoneum for reduction of shoulder-tip pain following laparoscopy. $\mathrm{Br} \mathrm{J}$ Surg., $87: 1161-5$.

12. Lewis RT, Goodall RG, Marien B, Park M, Lloyd-Smith W, Wiegand FM (1990): Simple elective cholecystectomy: To drain or not. Am J Surg., 159:241-5.

13. Askew JA (2005): Survey of current surgical treatment of gall stones in Queensland, Aust NZJ Surg., 75:10869.

14. Ishikawa K, Matsumata $T$, Kishihara F, Fukuyama Y, Masuda H, Kitano S (2011): Laparoscopic cholecystectomy with and without abdominal prophylactic drainage. Dig Endosc., 23(2):153-6.

15. El-Labban G, Hokkam E, EI-Labban M, Saber A, Heissam K, ElKammash S (2012): Laparoscopic elective cholecystectomy with and without drain: A controlled randomized trial. J Minim Access Surg., 8(3):90-2.

16. Kim EY, Lee SH, Lee JS, Yoon YC, Park SK, Choi HJ, Yoo DD, Hong TH (2015): Is routine drain insertion after laparoscopic cholecystectomy for acute cholecystitis beneficial? A multicenter, prospective randomized controlled trial. J Hepatobiliary Pancreat Sci., 22(7):551-7.

17. Georgiou C, Demetriou N, Pallaris T, Theodosopoulos T, Katsouyanni K, Polymeneas G (2011): Is the routine use of drainage after elective laparoscopic cholecystectomy justified? A randomized trial. $\mathrm{J}$ Laparoendoscopic Adv Surg Tech A., 21(2):119-23. 